\title{
Empirical study on sustainable supply chain strategies and its impact on competitive priorities: The mediating role of supply chain collaboration
}

\author{
Haitham M. Alzoubia ${ }^{a *}$, Gouher Ahmed ${ }^{b}$, Anwar Al-Gasaymeh ${ }^{c}$ and Barween Al Kurdid
}

${ }^{a}$ Associate Professor of Management, Skyline University College, UAE

${ }^{b}$ Professor of International Management, Skyline University College, UAE

${ }^{c}$ Assistant Professor of Banking and Finance, Applied Science Private University, Jordan

${ }^{d}$ Marketing Department, Amman Arab University, Amman, Jordan

\section{CHR O N I C E A B S T RACT}

Article history:

Received: June 252019

Received in revised format: July

292019

Accepted: September 4, 2019

Available online:

September 4, 2019

Keywords:

Sustainable Supply Chain Strate-

gies

Supply Chain Collaboration

Competitive Priorities

\begin{abstract}
Companies seek to adopt competitive strategies that achieve sustainability standards, not only in achieving economic success but also in serving society and preserving the environment at the same time. Pharmaceutical companies and their supply chains are facing increasing pressure to preserve the environment because of the problems caused by medical waste, and it is necessary to show their role through their strategies in preserving the environment and serving society as well. This study aims to investigate the relationship between sustainable supply chain strategies and supply chain collaboration and its effect on competitive priorities. The study investigates whether Jordanian Pharmaceutical companies incorporate the sustainability strategy into supply chain strategy, and whether that may impact its competitive priorities. The study population consists of (23) Jordanian Pharmaceutical companies. A structured questionnaire is designed and distributed among top managers in the surveyed companies. A Structural Equation Modeling technique is used to analysis the data and provide the results. Analysis proves the relationship between sustainable supply chain strategies and supply chain collaboration, where companies are interested in attaining some achievements in the area of social and environmental to gain some collaborative strategies with their partners in the supply chain. The study suggests that organizations may adopt the Triple Bottom Line (TBL) framework to evaluate their performance in a broader perspective and extend the collaboration with suppliers and customers through information sharing along the supply chain partners.
\end{abstract}

\section{Introduction}

Current government regulations, safety institutions and many studies encourage businesses to go beyond their financial interests to serve the society and secure the environment. Recent initiatives try to increase the environmental concern and call for improving the environment like going green, and apply corporate social responsibility (CSR) to increase the companies' accountability for taking care of society and environment (Yun et al., 2018; Ioannou, \& Serafeim , 2019). In other words, most organizations need sustainable world to survive and sustainability "as defined by The Center for Sustainable Enterprise" is stated as how to perform in effectively without harming the environment and people. Rudnicka (2016) considered sustainability in the supply chain as to achieve a balance between the economic success as well as serving the social and environmental dimensions. Liu et al. (2017) defined sustainable supply chain as how to gain a competitive advantage by improving the profitability and increasing the positive impact on people and decreasing the negative impact on environment. The Triple Bottom Line (also known as TBL or 3BL) is considered to be a strategic planning tool and measurement as well as an accounting framework that incorporates triple dimensions of performance: economic, social, and environmental. Many organizations have started adapting and implementing TBL approach for their supply chain strategies to express a broader perspec-

\footnotetext{
* Corresponding author.

E-mail address: haitham_zubi@yahoo.com (H. M. Alzoubi) 
tive in order to gain a competitive advantage and to survive in the hyper competitive markets (Ha-Brookshire, 2017; Amponsah \& Ahmed, 2017a,b). Sustainability issues have been highlighted the most at pharmaceutical sector in the industrial sustainability, to assist companies successfully achieve sustainable pharmaceutical products and services in their production and operations specially in supply chain management. Many pharmaceutical companies consider the cost savings benefits in their production and operations. Meanwhile, they are facing a challenge of reducing the environmental impact of pharmaceutical production by attempting to minimize the effect of supply chain activities on their ecological system, and protecting the environment (Bravo \& Carvalho, 2013).

\section{Theoretical background}

Sustainability in supply chain has drawn researchers' attention at the time that the global warning about environment has increased. The supply chain in the organizations is accounted for $12.9 \%$ of the environmental pollution, and a major source of toxic waste, water and air pollution, as well as gas emissions and energy misuse (Intergovernmental Panel on Climate Change, IPCC, 2016). These higher emissions are threatening the environment unless sustainable supply chain activities are planned to enhance efficiency. Therefore, including social and environmental dimensions in the sustainable supply chain strategies is requested globally. Nowadays, many types of pressures are used to force organizations to reduce their negative impacts to the environment and to enhance a fair social life all over the world (Ahmed, 2013; Hsu et al., 2016). The current understanding regarding any sustainable initiative or activity could be linked to its cost benefit analysis. Managers generally take decisions to be aligned with their strategic direction that should lead to achieve economic benefits. Some think that any contribution to sustainable activities have to be economically perceived. Increasingly pressures from various stakeholders are seeking the best procedures to enhance the sustainability while we maintain a good performance. Recent studies have proposed conceptual frameworks and practices to be included in strategies for supply chain management. Similarly, such issues of sustainability that could be applicable to all companies include social responsibility issues, compliance, human rights, equity, fair wages, social welfare, health and safety, ethics, transparency and nondiscrimination, green supply chain, environmental friendly products, preserve the resources, and 'end of life' assessment (Alzoubi, 2018; Abidi et al., 2017; Amponsah \& Ahmed, 2017b).

Rudnicka (2016) recommended sustainability practices across supply chains, which included: assuring suppliers support, orientation, cognition, conceptualize supply chain and commonality and supply chain measurement. However, Schaltegger et al. (2014) focused on environmental sustainability and put more emphasis on CSR reports. Their findings were supported to integrate and improve triple bottom line within ten dimensions. These ten dimensions include: internal supply chain, external environment, institutional pressure, health and safety, community focus, energy, risk management, measures, customer orientation, and go-green. Moreover, Schaltegger et al. (2014) developed a framework that support the relationship between organization's sustainability performance and sustainable supply chain management. Results assure that entrepreneurial activities and strategic procurement had significant impacts on improving sustainability and sustainable supply chain management. Many approaches and methods have been used to measure environmental and social along with profitability in the supply chain management. Even though there are no common reporting standards for these metrics. However, some studies have been found to recommend adopting TBL approach in sustainable supply practices and organizational sustainability which address social and environmental issues along economic issues. Arora (2014) examined the strategic orientation of the sustainable supply chain, and developed a model by examining a 7-strategies for sustainable supply chain using the triple bottom line approach. Ortas et al. (2014) aimed to create integrated values and they not only focused on economic values by maximizing profits, but also adopted a stronger responsibility to create social values which includes: offering good jobs, impose equality and quality training and encourage innovations, while the environmental values include: responsible consumption, renewable energy and clean water and sanitation, by maximizing positive impact while minimizing negative impact. Yun et al., (2018) and Alzoubi and Ahmed (2019) recommended three dimensions of implementing triple bottom line approach in sustainable supply chain management including: maximizing economic benefits, minimizing negative effect on environment and benefits to society.

Success in sustainability cannot be established without collaboration and integration and real commitment. All internal and external members of the supply chain should be truly sustainable, also companies' departments, and individuals who work in company have to be sustainable. Moreover, companies' external partners must be sustainable as well. Supply chain must play a significant role through procurement decisions to shape the supplier relationships that focus via suppliers' collaboration to reduce the environmental impacts and priorities the suppliers relative to their environmental impacts, and encourage the suppliers to report based on their environmental impact (Chin et al., 2015). These integrated practices not only support collaborated inbound logistics but also involve the clients. An organization should develop better strategies to align the supply chain sustainability with supply chain collaboration by building good relationship with internal stakeholders, employees, customers and suppliers. Effective and efficient use of supply chain activities resources should lead to enhance the performance, and should design based on competitive priorities. Competitive priorities are a strategic choice in sustainable supply chain to maintain its performance. This approach is considered critical as organizations understand that social and environmental as well as profitability of sustainable supply chain could impact on company choice of competitive priorities. Companies try to choose their priorities like lead time-based priority, dependability-based priority and cost-based priority by trade off some benefits with stockholders (Lin \& Tseng, 2016). The pharmaceutical industry in Jordan has witnessed a significant growth, 
taking an important position among the various industrial sectors and is considered as the second sector in terms of contribution to the gross domestic product in Jordan. The number of registered companies as pharmaceutical factories in Jordan is 23 . The Jordanian pharmaceutical sector has more than a thousand of registered International brands of medicine and drugs. The pharmaceutical manufacturing is the biggest producer in the Middle East known in the area as well-developed gaining advantage of high quality's reputation. The pharmaceutical sector is ranked third in the Jordanian's exports, and it exports $70 \%$ of the total Jordanian pharmaceutical production to more than 65 countries around the world. There are about 5 thousand employees working in the pharmaceutical sector, 39\% of whom are women. However, pharmaceutical sector in Jordan is considered as a supportive sector for ladies and it is one of the best for the empowering women. In addition, the holders of university and higher degrees (diploma, bachelor, master and doctorate) represent more than $67 \%$ of the total number of employees, showing that the pharmaceutical is based on high educated capabilities of human resources.

\section{Conceptual Framework and Hypotheses Development}

\subsection{Conceptual Framework and study model}

Based on the literature review we present a causal model to describe the assumptions that map the relationships between sustainable supply chain strategies, supply chain collaboration and competitive priorities in pharmaceutical companies. The proposed model shows that sustainable supply chain strategies are supposed to be significant determinant of competitive priorities, while the supply chain collaboration is considered to be as mediator in this relationship.

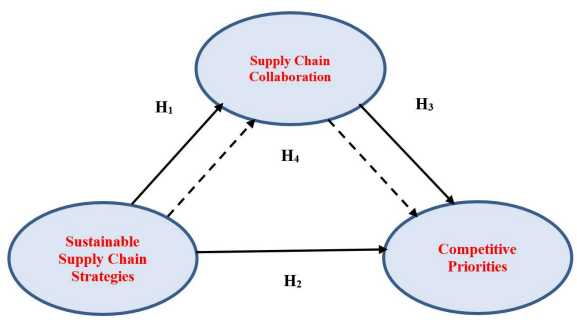

Fig. 1. The proposed Model of the Study

\subsection{Study Hypotheses}

Fig. 1 shows the structural model of the study and how the relationships are connecting the variables of the study, and in order to examine the validity of the proposed model, we propose the following hypotheses:

$\mathrm{H}_{1}$ : Sustainable supply chain strategies have positive direct effects on supply chain collaboration at pharmaceutical companies in Jordan.

$\mathrm{H}_{2}$ : Sustainable supply chain strategies have positive direct effects on competitive priorities at pharmaceutical companies in Jordan.

$\mathrm{H}_{3}$ : Supply chain collaboration have positive direct effects on competitive priorities at pharmaceutical companies in Jordan.

$\mathrm{H}_{4}$ : Sustainable supply chain strategies have positive indirect effects on competitive priorities through supply chain collaboration as mediator at pharmaceutical companies in Jordan.

\section{Study Methodology}

The research design of this study is considered as an empirical, exploratory and descriptive study, where we attempt to understand the causes and effects among the sustainable supply chain strategies, supply chain collaboration and competitive priorities. The study aimed to empirically investigate the direct and indirect effects of sustainable supply chain strategies as perceived by managers on competitive priorities at pharmaceutical companies through supply chain collaboration as mediator.

\subsection{Population and Sample}

The study population are the 23 Pharmaceutical organizations that involve in drugs production industry in Jordan according to Jordan Business Guide 2017. The study has followed a comprehensive sample by considering all Pharmaceutical companies in Jordan. The unit of analysis consisted of all top managers in the surveyed companies and175 valid questionnaires were used for data analysis.

\subsection{Data Analysis}

A statistical SmartPLS software package was used to analysis the data in order to understand the direct and indirect effect of sustainable supply chain strategies on competitive priorities at pharmaceutical companies in Jordan. The questionnaire was considered as the study tool to measure the study variables and it was constructed on a five-point Likert-type scale with 
anchors of ( $1=$ 'strongly disagree') and ( 5 = 'strongly agree'). However, sustainable supply chain strategies were composed of three dimensions (maximize economic benefits, minimize negative effect on environment, and maximize benefits to society) and was assessed with 12 items. Supply chain collaboration variable was composed of three dimensions (supplier collaboration, internal collaboration and customer collaboration) and was assessed with 12 items. Competitive priorities variable was composed of three dimensions (lead-time-based priority, dependability-based priority and cost-based t priority) and was assessed with 12 items. Exploratory factor analysis was used to describe and examine the measures. Cronbach's alpha was also used to measure the consistency of each part of the measure, varimax rotation of exploratory factor analysis helped to determine which questions considered to be best to measure the study variables and dimensions and deleting a cross-loaded item from the scale if necessary. Cronbach's alpha coefficient was used to examine the internal consistency. Table 1 shows acceptable levels of reliability to all study constructs, where the reliability coefficient was ranging between 0.778 and 0.878 , and all constructs were above (0.7) (Hair et al., 2010), this indicator helps us learn about that the design and the scale of the questionnaire and whether the items in the questionnaire were able to represent each variable of the study.

Table 1

Cronbach's Alpha Coefficient for Study variables

\begin{tabular}{lll}
\hline Number & Construct & $\alpha$ \\
\hline 1 & Sustainable Supply Chain Strategies & 0.788 \\
2 & Supply Chain Collaboration & 0.807 \\
3 & Competitive Priorities & 0.778 \\
& All & 0.878 \\
\hline
\end{tabular}

Descriptive statistics of study variables: sustainable supply chain strategies, supply chain collaboration, competitive priorities are illustrated in Table 2, Table 3 and Table 4, respectively. All values fall in the medium level of importance since the medium values should be between 2.33 and 3.66 (Hair et al., 2010).

Table 2

Descriptive statistics for Sustainable Supply Chain Strategies

\begin{tabular}{lllll}
\hline Item & Dimension & Mean & Standard Deviation & Level of Importance \\
\hline 1 & Maximize economic benefits & 3.15 & 0.731 & Medium \\
2 & Minimize negative effect on environment & 3.22 & 0.801 & Medium \\
3 & Maximize benefits to society & 2.98 & 0.894 & Medium \\
\hline
\end{tabular}

Table 3

Descriptive statistics for Supply Chain Collaboration

\begin{tabular}{lllll}
\hline Item & Dimension & Mean & Standard Deviation & Level of Importance \\
\hline 1 & Supplier collaboration & 2.88 & 0.966 & Medium \\
2 & Internal collaboration & 3.01 & 0.885 & Medium \\
3 & Customer collaboration & 3.31 & 0.788 & Medium \\
\hline
\end{tabular}

Table 4

Descriptive statistics for Competitive Priorities

\begin{tabular}{lllll}
\hline Item & Dimension & Mean & Standard Deviation & Level of Importance \\
\hline 1 & Leadtime-based Priority & 3.11 & 0.792 & Medium \\
2 & Dependability-based Priority & 3.16 & 0.751 & Medium \\
3 & Cost-based Priority & 2.93 & 0.917 & Medium \\
\hline
\end{tabular}

Based on the data of the goodness-of-fit shown in Table 5 for the path model, we have concluded that the measurement models provided yield acceptable fit to the data, and this confirms the structural equation model of the study fits the sample data.

Table 5

Goodness of Fit statistics for the structural model

\begin{tabular}{llllllll}
\hline Chi- Square $\chi^{2}$ & D.F & Chi-Square / D.F & Sig & NFI & CFI & GFI & RAMSA \\
\hline 30.054 & 8 & 3.757 & .000 & .878 & .917 & .948 & .109 \\
\hline
\end{tabular}

GFI: Goodness of fit index NFI: The Bentler-Bonett normed fit index CFI: The comparative fit index RMSEA: Root Mean Square Error of Approximation

\section{Hypotheses Tests}

For testing the hypotheses and before doing path analysis, we have conducted the multicollinearity test to make sure there is no high correlation between dimensions of each variable. Results of multicollinearity show that there is no abnormal correlation between dimensions of variables. To test the hypotheses and to examine the effect and the significance level of each path in the model, we ran a structural equation modeling as shown in Fig. 1. The path model indices indicate the model's goodnessof-fit, and ensure an acceptable fit to the data to the model presented in Table 5 as the following: Chi square/D.F (30.054/8) was (3.757), while (GFI) Goodness of fit index was (0.948) (range between 0 to 5, the fewer the better), (NFI) Normed fit index was (0.878), (CFI) Comparative fit index (the revised form of the NFI) was (0.917) (both NFI, CFI range between 0 to 1 , values closer to 1 indicating good model fit), and the Root mean square error of approximation (RMSEA) was (0.109) (values range between 0 to 1 , values closer to 0 indicating good model fit) (Hair et al. 2010). Therefore, we conclude from all 
model fit indices that the overall fit of the model is approved for continuing of hypothesis testing to examine the causal relationships between the study variables.

Table 6

Direct, Indirect, \& total effect for path analysis

\begin{tabular}{|c|c|c|c|c|c|c|}
\hline \multirow[b]{2}{*}{$\begin{array}{l}\text { From } \\
\text { To }\end{array}$} & \multicolumn{2}{|c|}{ Direct Effect } & \multicolumn{2}{|c|}{ Indirect Effect } & \multicolumn{2}{|c|}{ Total Effect } \\
\hline & $\begin{array}{l}\text { Sustainable Sup- } \\
\text { ply Chain Strate- } \\
\text { gies }\end{array}$ & $\begin{array}{l}\text { Supply Chain Col- } \\
\text { laboration }\end{array}$ & $\begin{array}{l}\text { Sustainable Sup- } \\
\text { ply Chain Strate- } \\
\text { gies }\end{array}$ & $\begin{array}{l}\text { Supply Chain Col- } \\
\text { laboration }\end{array}$ & $\begin{array}{c}\text { Sustainable Sup- } \\
\text { ply Chain Strate- } \\
\text { gies }\end{array}$ & $\begin{array}{l}\text { Supply Chain Col- } \\
\text { laboration }\end{array}$ \\
\hline $\begin{array}{l}\text { Supply Chain Col- } \\
\text { laboration }\end{array}$ & .451 & .000 & .000 & .000 & .451 & .000 \\
\hline $\begin{array}{l}\text { Competitive Prior- } \\
\text { ities }\end{array}$ & .181 & .370 & .197 & .000 & .367 & .374 \\
\hline
\end{tabular}

The analysis shown in Table 6, presents standardized path coefficients of the study model (beta coefficients in which the estimates results taken from a regression analysis). Table 6 and Fig. 2 illustrate that the path coefficients from sustainable supply chain strategies to supply chain collaboration was positive and significant (Standardized coefficient $=0.45 ; \mathrm{p}<.05$ ), the path coefficients from sustainable supply chain strategies to competitive priorities was positive and significant (Standardized coefficient $=0.18 ; \mathrm{p}<.05$ ). Therefore, there is enough evidence to support $\mathrm{H}_{1}$ and $\mathrm{H}_{2}$. The path coefficients from supply chain collaboration to competitive priorities was also positive and significant (Standardized coefficient $=0.37 ; \mathrm{p}<.05$ ), Therefore, there we can support $\mathrm{H}_{3}$. The indirect effect of sustainable supply chain strategies on competitive priorities through supply chain collaboration as mediator was also positive and significant (indirect standardized coefficient $=0.197 ; \mathrm{p}<.05$ ), that means that $\mathrm{H}_{4}$ is also supported. Therefore, the results have supported all hypotheses.

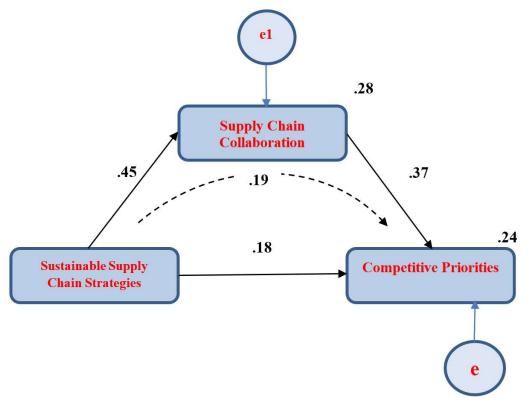

Fig. 2. Result of path analysis

Table 7

Hypotheses testing results

\begin{tabular}{|c|c|c|c|}
\hline Hypothesis & Causal path & $\begin{array}{l}\text { Standardized } \\
\text { Coefficients }\end{array}$ & Test result \\
\hline H1 & Sustainable Supply Chain Strategies on Supply Chain Collaboration & $0.45^{*}$ & supported \\
\hline $\mathrm{H} 2$ & Sustainable Supply Chain Strategies on Competitive Priorities & $0.17 *$ & supported \\
\hline $\mathrm{H} 3$ & Supply Chain Collaboration on Competitive Priorities & $0.37 *$ & supported \\
\hline $\mathrm{H} 4$ & $\begin{array}{l}\text { Indirect effect of Sustainable Supply Chain Strategies on Competitive Priorities through } \\
\text { Supply Chain Collaboration as mediator }\end{array}$ & $0.197 *$ & supported \\
\hline
\end{tabular}

* Significant at a level of $(\alpha \leq 0.05)$.

The results presented in Table 7 show the hypotheses' testing. The previous results have proved that the study model fit to test the study's hypotheses, and Table 7 have shown that all hypotheses are accepted and approved. Fig. 2 shows coefficient of determination $\left(\mathrm{R}^{2}\right)$ (the part of the variance in the dependent variable that is predictable from the independent variable, range between 0 and 1 the highest the better). The results illustrated in Fig. 2 show that sustainable supply chain strategies account for $28 \%$ of variance in supply chain collaboration; sustainable supply chain strategies and supply chain collaboration, account for $24 \%$ of variance in competitive priorities.

\section{Conclusion}

Sustainability is becoming one concern of strategic planning for many organizations and it seems to continue to have an impact on strategic decisions. Moreover, top management needs to seriously reconsider incorporating sustainability within their organizations' strategies and supply chains' strategies as well. At the same time, increasing the level of internal and external collaboration among all supply chain parties to maintain their competitive priorities is needed. It is a challenging decision that requires a sound management framework to focus on environmental and social performance along with financial performance. The study has provided a framework for managers to address sustainability in their supply chain strategies and supply chain collaboration that may result in different competitive priorities. The results have provided an empirical evidence 
of the link among sustainable supply chain strategies, supply chain collaboration and competitive priorities. Hypotheses testing has confirmed the mediating effect of supply chain collaboration on the relationship between sustainable supply chain strategies and competitive priorities at the Pharmaceutical companies in Jordan. It has been observed from the analysis that most companies which tend to expand their sustainable strategies prioritize the dependability-based advantage over the costbased advantage as a key driver of customer satisfaction. Moreover, the results have determined that companies with less implementation of sustainable supply chain issues could chose the cost-based advantage as their first priority. Additionally, collaboration and interactions with suppliers noted to have more practice with companies concerning sustainability. We also encourage the companies to increase their focus on the social and environmental issues within their supply chain. Likewise, companies should increase the level of information sharing and collaboration and should take the different issues when developing relationships with suppliers and customers to ensure better implementation on social and environmental issues. Although companies sometimes have to do some tradeoffs to prioritize their competitive advantages in order to expand the implementation of sustainable supply chain strategies.

The study tries to contribute to the body of knowledge about the level of perception and implementation of sustainability in supply chain. The study has investigated the relationship of sustainable supply chain strategies and supply chain collaboration on competitive priorities in Jordanian Pharmaceutical industry, and discussed the trade-off between achieving economic objectives with the competitive priorities. A future research may examine the sustainable relationship to other disciplines in business rather than supply chain. Moreover, we need to investigate the factors stimulate organizations to adopt sustainability in supply chain rather than stakeholder's pressures and governmental policies and test this relationship for different industries.

\section{References}

Abidi, N., Bandyopadhayay, A., \& Gupta, V. (2017). Sustainable supply chain management: A three dimensional framework and performance metric for Indian IT product companies. International Journal of Information Systems and Supply Chain Management (IJISSCM), 10(1), 29-52.

Alzoubi, H., \& Ahmed, G. (2019). Do TQM practices improve organisational success? A case study of electronics industry in the UAE. International Journal of Economics and Business Research, 17(4), 459-472.

Ahmed, G. (2013). The Recessionary Global Business Environment. Global Journal of Research in Management, 3(2), 1-14.

Alzoubi, H. (2018). The role of intelligent information system in e-supply chain management performance. International Journal of Multidisciplinary Thought, 7(2), 363-370.

Amponsah, C. T., \& Ahmed, G. (2017a). Factors affecting entrepreneurship in emerging economies: a case of Dubai. Journal for International Business and Entrepreneurship Development, 10(2), 120-137.

Amponsah, C. T., \& Ahmed, G. (2017b). New global dimensions of business excellence. International Journal of Business Excellence, 13(1), 60-78.

Arora, A. (2014) Sustainability Strategies in Supply Chain Management. Unpublished master thesis, Georgia Southern University, Georgia

Schaltegger, S., Burritt, R., Bai, C., \& Sarkis, J. (2014). Determining and applying sustainable supplier key performance indicators. Supply Chain Management: An International Journal, 19(3), 275-291.

Bravo, A. M. S., \& de Carvalho, J. C. (2013). Understanding pharmaceutical sustainable supply chains-a case study application. Independent Journal of Management \& Production, 4(1), 228-247.

Chin, T. A., Tat, H. H., \& Sulaiman, Z. (2015). Green supply chain management, environmental collaboration and sustainability performance. Procedia Cirp, 26, 695-699.

Ha-Brookshire, J. (2017). Toward moral responsibility theories of corporate sustainability and sustainable supply chain. Journal of Business Ethics, 145(2), 227-237.

Hair, J. F., Black, W. C., Babin, B. J., Anderson, R. E., \& Tatham, R. L. (2006). Multivariate data analysis 6th Edition. Pearson Prentice Hall. New Jersey. humans: Critique and reformulation. Journal of Abnormal Psychology, 87, 49-74.

Hsu, C. C., Tan, K. C., \& Mohamad Zailani, S. H. (2016). Strategic orientations, sustainable supply chain initiatives, and reverse logistics: Empirical evidence from an emerging market. International Journal of Operations \& Production Management, 36(1), 86-110.

Ioannou, I. \& Serafeim, G. (2019). Yes, Sustainability Can Be a Strategy. Harvard Business Review, February. 1-4.

Lin, Y. H., \& Tseng, M. L. (2016). Assessing the competitive priorities within sustainable supply chain management under uncertainty. Journal of Cleaner Production, 112, 2133-2144.

Liu, W., Bai, E., Liu, L., \& Wei, W. (2017). A framework of sustainable service supply chain management: A literature review and research agenda. Sustainability, 9(3), 421.

Ortas, E., M. Moneva, J., \& Álvarez, I. (2014). Sustainable supply chain and company performance: A global examination. Supply Chain Management: An International Journal, 19(3), 332-350.

Rudnicka, A. (2016). How to manage sustainable supply chain? The issue of maturity. LogForum, 12(4), 203-211.

Schaltegger, S., Burritt, R., Varsei, M., Soosay, C., Fahimnia, B., \& Sarkis, J. (2014). Framing sustainability performance of supply chains with multidimensional indicators. Supply Chain Management: An International Journal, 19(3), 242-257.

Yun, G., Yalcin, M. G., Hales, D. N., \& Kwon, H. Y. (2019). Interactions in sustainable supply chain management: a framework review. The International Journal of Logistics Management, 30(1), 140-173.

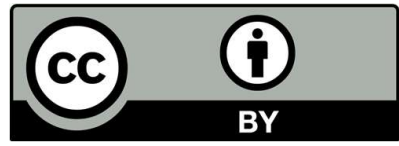

(C) 2020 by the authors; licensee Growing Science, Canada. This is an open access article distributed under the terms and conditions of the Creative Commons Attribution (CCBY) license (http://creativecommons.org/licenses/by/4.0/). 